\title{
Effects of Air Temperature and Precipitation on Soil Moisture on the Qinghai-Tibet Plateau during the 2015 Growing Season
}

\author{
Qingyan Xie, ${ }^{1}$ Jianping $L i \mathbb{D}^{2,3}$ and Yufei Zhao ${ }^{4}$ \\ ${ }^{1}$ College of Global Change and Earth System Sciences (GCESS), Beijing Normal University, Beijing 100875, China \\ ${ }^{2}$ Frontiers Science Center for Deep Ocean Multispheres and Earth System (FDOMES), Key Laboratory of Physical Oceanography, \\ Institute for Advanced Ocean Studies, Ocean University of China, Qingdao 266100, China \\ ${ }^{3}$ Laboratory for Ocean Dynamics and Climate, Pilot Qingdao National Laboratory for Marine Science and Technology, \\ Qingdao 266237, China \\ ${ }^{4}$ National Meteorological Information Centre, China Meteorological Administration, Beijing 100081, China
}

Correspondence should be addressed to Jianping Li; ljp@ouc.edu.cn

Received 20 September 2019; Revised 29 June 2020; Accepted 9 July 2020; Published 1 August 2020

Academic Editor: Antonio Donateo

Copyright (C) 2020 Qingyan Xie et al. This is an open access article distributed under the Creative Commons Attribution License, which permits unrestricted use, distribution, and reproduction in any medium, provided the original work is properly cited.

\begin{abstract}
The Qinghai-Tibet Plateau (QTP) holds massive freshwater resources and is one of the most active regions in the world with respect to the hydrological cycle. Soil moisture (SM) plays a critical role in hydrological processes and is important for plant growth and ecosystem stability. To investigate the relationship between climatic factors (air temperature and precipitation) and SM during the growing season in various climate zones on the QTP, data from three observational stations were analyzed. The results showed that the daily average $\left(\mathrm{T}_{\text {ave }}\right)$ and minimum air temperatures $\left(\mathrm{T}_{\min }\right)$ significantly influenced SM levels at all depths analyzed (i.e., 10, 20, 30, 40, and $50 \mathrm{~cm}$ deep) at the three stations, and $\mathrm{T}_{\min }$ had a stronger effect on $\mathrm{SM}$ than did $\mathrm{T}_{\text {ave }}$. However, the daily maximum air temperature $\left(\mathrm{T}_{\max }\right.$ ) generally had little effect on $\mathrm{SM}$, although it had showed some effects on SM in the middle and deeper layers at the Jiali station. Precipitation was an important factor that significantly influenced the SM at all depths at the three stations, but the influence on SM in the middle and deep layers lagged the direct effect on near-surface SM by 5-7 days. These results suggest that environment characterized by lower temperatures and higher precipitation may promote SM conservation during the growing season and in turn support ecosystem stability on the QTP.
\end{abstract}

\section{Introduction}

The Qinghai-Tibetan Plateau (QTP) is the highest plateau in the world [1], with an average altitude greater than $4000 \mathrm{~m}$, and covers an area of $2.5 \times 10^{6} \mathrm{~km}^{2}$. The low temperatures support many glaciers and a thick layer of permafrost. The QTP is the headwater region of many of Asia's largest rivers [2-4], such as the Yangtze, Yellow, and Yarlung Zangbo rivers. Consequently, the QTP is known as "the water tower of Asia" on account of its key role in the hydrological cycle [5], and its abundant water resources have a significant impact on global and regional climate systems, including the Asian monsoon, as well as on its ecosystems and inhabitants $[3,6]$. However, QTP is one of the most weak regions in the world under global warming and climate change; its ecosystem security, nutrient cycling, biomass, and society function are all facing serious challenges and high risks [1-3]. For example, Fan et al. [7] reported that between 1961 and 2016, the QTP's annual maximum and minimum temperatures showed a marked increasing trend, which may heighten the challenges affecting ecosystems on the QTP. Other studies have suggested that global warming might not only have accelerated ice melting and increased surface runoff over recent decades but also increase rate of evaporation, increase or decrease soil moisture, and lead to a big uncertainty of this problem, further affecting sensitive ecosystems on the QTP $[2,8,9]$.

Soil moisture (SM) is one of the important parts of the hydrological cycle in ecosystems and climatic system and has a direct influence on vegetation growth and ecosystem 
stability $[10,11]$. Seneviratne et al. [11] pointed out that an important influence on near-surface soil moisture was related to air temperature, in particular, the effects of SMtemperature coupling and feedback between these two variables. Although SM-precipitation coupling has been investigated for at least several decades, little attention has been given to SM on the QTP [12, 13]. Yang et al. [3] reported that high SM levels in April and May were caused by thawing driven by rising air temperatures and that precipitation caused SM increase on the QTP between June and September. Changes in SM caused by air temperature and precipitation may lead to different greenhouse gases flux from alpine meadows, which are an important carbon (C) and nitrogen $(\mathrm{N})$ pool on the QTP [14]. Increased SM on the QTP may also lead to an increase in precipitation over eastern China and a decrease over the south China region [6].

Furthermore, the large area and variation in elevation of the QTP mean that it experiences many different climate zones, and thus the natural vegetation species were diverse, with forest, alpine steppe, meadow, wetland, desert, and valley agriculture all being found on the plateau [9]. In addition, the severe environment and cold, arid climate cause the soil to freeze in mid-October to November, and this freezing persists for nearly six months until the following April or May, when the ground starts to thaw again [3]. Therefore, the growing season on the QTP is too short, approximately six months from May to October in every year. However, the relationships between SM and climatic factors (air temperature and precipitation) among site scale with different climate patterns on QTP are still unclear during growing season, especially for the daily minimum, average, and maximum air temperature, and this problem is much important for plant growth and ecosystem stability.

Thus, to investigate how SM is affected by changes in air temperature and precipitation during the growing season at sites on the QTP with differing altitudes, climatic conditions, and vegetation patterns, the data were obtained from three observational stations in the central Tibet Autonomous Region (TAR), near the TAR's capital, Lhasa. These three sites each have different climate patterns, and the relationships between SM at various depths and air temperature and precipitation during one growing season (May-October 2015) were analyzed below. Investigating how SM at different depths responds to changes in air temperature and precipitation through the growing season will help us better understand the key role of SM with respect to the ecosystems and climate on the QTP.

\section{Data and Methodology}

2.1. Study Sites. The three climate observation stations used here, at Naqu, Zedang, and Jiali, are at elevations of $4507 \mathrm{~m}$, $3560 \mathrm{~m}$, and $4488 \mathrm{~m}$, respectively (Figure 1). Naqu is located in an alpine subfrigid and semiarid climate zone, with an average annual air temperature of $-2.1^{\circ} \mathrm{C}$ and an annual precipitation in the range $247-514 \mathrm{~mm}$. The main ecosystems are alpine steppe and alpine meadow, and this is an important pasturing area in Tibet [15]. Zedang belongs to the alpine temperate semiarid monsoon climate zone, with an average annual air temperature of $7.5^{\circ} \mathrm{C}$ and an annual precipitation in the range $302-446 \mathrm{~mm}$, and is a main agricultural region in Tibet [16]. Jiali belongs to the alpine subfrigid semihumid monsoon climate zone and is the most humid area on the QTP, with the South Asian monsoon bringing large amounts of moisture and rainfall each summer. The annual average air temperature is $-0.4^{\circ} \mathrm{C}$, and the annual precipitation is between 522 and $958 \mathrm{~mm}$, with an annual average of $719 \mathrm{~mm}[17,18]$.

2.2. Data. Daily air temperature $\left({ }^{\circ} \mathrm{C}\right)$, daily precipitation $(\mathrm{mm})$, and hourly soil moisture (\%) data from the three stations for the period May to October 2015 were provided by the China Meteorological Administration. Daily air temperature data comprised the average $\left(\mathrm{T}_{\mathrm{ave}}\right)$, maximum $\left(\mathrm{T}_{\max }\right)$, and minimum $\left(\mathrm{T}_{\min }\right)$ temperatures. Hourly soil moisture (SM) data were recorded at depths of 10 and $20 \mathrm{~cm}$ (shallow layer), 30 and $40 \mathrm{~cm}$ (middle layer), and $50 \mathrm{~cm}$ (deep layer). These hourly SM data were switched into daily data with the average daily SM being used as the SM value for each day.

\section{Results}

3.1. Effects of Air Temperature on Soil Moisture. The relationships between $\mathrm{T}_{\text {ave }}, \mathrm{T}_{\max }, \mathrm{T}_{\min }$, and $\mathrm{SM}$ at the different depths for all three stations were analyzed. At Naqu, the average values of $\mathrm{T}_{\text {ave }}, \mathrm{T}_{\max }$, and $\mathrm{T}_{\min }$ from 1 May to 31 October 2015 were $7.1^{\circ} \mathrm{C}, 14.6^{\circ} \mathrm{C}$, and $0.8^{\circ} \mathrm{C}$, respectively. Both $\mathrm{T}_{\mathrm{ave}}$ (Figures 2(a)-2(e)) and $\mathrm{T}_{\text {min }}$ (Figures 2(k)-2(o)) were significant related to SM at different depths, with the strength of the relationship (as assessed by correlation coefficients) decreasing from shallow to deep. However, $\mathrm{T}_{\max }$ (Figures 2(f)-2(j)) had no significant effect on SM. In addition, the correlation coefficients between $\mathrm{T}_{\min }$ and $\mathrm{SM}$ were greater than those between $\mathrm{T}_{\text {ave }}$ and $\mathrm{SM}$ at all depths. These results showed that higher air temperatures probably have no or little effect on SM but that lower temperatures might be closely related to $\mathrm{SM}$ at Naqu.

In Figures 2-4, the solid green dots indicate the average air temperature, the solid red dots indicate the maximum air temperature, and the solid blue dots indicate the minimum air temperature.

At Zedang, the average values of $\mathrm{T}_{\text {ave }}, \mathrm{T}_{\max }$, and $\mathrm{T}_{\min }$ during the growing season in 2015 were $13.9^{\circ} \mathrm{C}, 22.2^{\circ} \mathrm{C}$, and $7.8^{\circ} \mathrm{C}$, respectively. As Zedang has the lowest altitude $(3560 \mathrm{~m})$ of the three sites used in this study, it shows the highest air temperatures of the three stations. Figure 3 shows the correlation coefficients between $\mathrm{T}_{\text {ave }}$ (Figures 3(a)-3(e)), $\mathrm{T}_{\max }$ (Figures 3(f)-3(j)), $\mathrm{T}_{\min }$ (Figures 3(k)-3(o)), and $\mathrm{SM}$ through the soil profile from Zedang. As with $\mathrm{Naqu}, \mathrm{T}_{\text {ave }}$ and $\mathrm{T}_{\text {min }}$ both showed significant effects on $\mathrm{SM}$, and the correlation coefficients between $T_{\min }$ and $S M$ were greater than those between $\mathrm{T}_{\text {ave }}$ and $\mathrm{SM}$ at all depths. Also similar to $\mathrm{Naqu}$, except for the $10 \mathrm{~cm}$ depth (Figure 3(f)), $\mathrm{T}_{\max }$ had no significant influence on SM. These results showed that the maximum air temperatures affected only the near-surface 


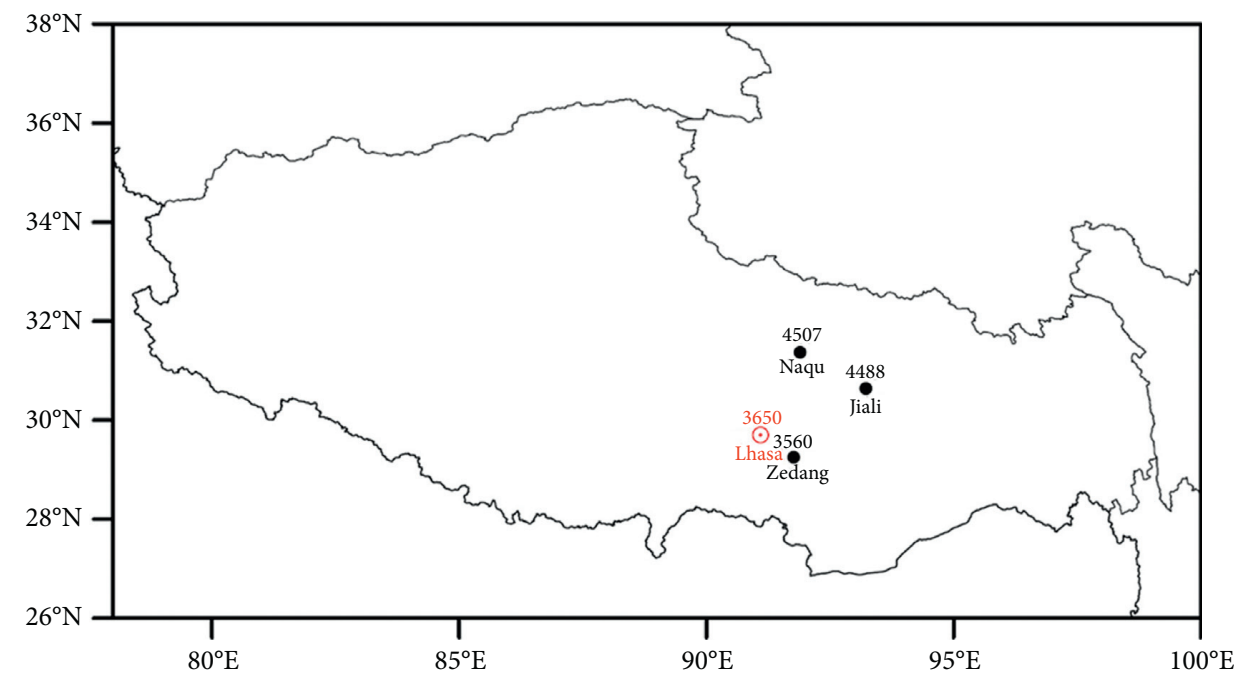

FIGURE 1: Locations of the study sites. Black solid dots are the three stations, and the red circle is the TAR capital Lhasa; the numbers indicate the altitude $(\mathrm{m})$ at each location.

SM levels; however, in comparison, the minimum air temperatures had a strong effect on SM at all depths at Zedang.

At Jiali, the average $T_{\text {ave }}, T_{\max }$, and $T_{\min }$ values for the 2015 growing season were $6.5^{\circ} \mathrm{C}, 13.9^{\circ} \mathrm{C}$, and $1.1^{\circ} \mathrm{C}$, respectively, similar to the values recorded at Naqu. Figure 4 shows the correlation coefficients between $\mathrm{SM}$ and $\mathrm{T}_{\text {ave }}$ (Figures 4(a)-4(e)), $\mathrm{T}_{\max }$ (Figures 4(f)-4(j)), and $\mathrm{T}_{\min }$ (Figures $4(\mathrm{k})-4(\mathrm{o})$ ) at the different depths at Jiali. As for Naqu and Zedang, $\mathrm{T}_{\text {ave }}$ and $\mathrm{T}_{\min }$ at Jiali both have significant effects on SM, and the correlation coefficients between $\mathrm{T}_{\text {min }}$ and $\mathrm{SM}$ were higher than those for $\mathrm{T}_{\mathrm{ave}}$ and $\mathrm{SM}$ at all depths. However, in contrast to Zedang, $\mathrm{T}_{\max }$ showed no influence on SM in shallow layers (Figures 4(f), 4(g)) but significantly influenced SM in the middle and deep layers of the soil (Figures 4(h)-4(j)). These results suggested that shallow SM levels may respond only to lower air temperatures at Jiali, but $\mathrm{SM}$ in the middle and deeper layers are insensitive to air temperature change, although the extent of the response differs with different air temperatures.

3.2. Effects of Precipitation on Soil Moisture. In Naqu, $272.3 \mathrm{~mm}$ of precipitation fell between May and October in 2015. There were two main periods of rainfall: 10 June to 10 July and 5 August to 20 September, during which there was $116 \mathrm{~mm}$ of rainfall in each period. Fluctuations in SM levels through the soil profile followed this pattern of precipitation (Figure 5), with $\mathrm{SM}$ in the shallow soil (depths of 10 and $20 \mathrm{~cm}$ ) being closely related to precipitation (Table 1). Although precipitation had no direct effect on SM in the middle and deep layers, which showed a lagged relationship with rainfall, with the strongest response appearing 5 to 7 days after the precipitation fell (Table 2).

In Figures 5-7, the hollow bars indicate precipitation, and the black, red, green, blue, and purple lines indicate SM at depths of $10,20,30,40$, and $50 \mathrm{~cm}$, respectively.
The total amount of precipitation during the growing season of 2015 at Zedang was $256 \mathrm{~mm}$, which is similar to the amount that fell at Naqu. At Naqu, there were also two main periods of rainfall, namely, 20 June to 20 July and 5 August to 5 September, with precipitation amounts of $71 \mathrm{~mm}$ and $138 \mathrm{~mm}$, respectively (Figure 6). Precipitation had a significant directly influence on SM at all five depths (Table 3). However, the correlation coefficient of $10 \mathrm{~cm} \mathrm{SM}$ was much greater than that at the other depths, which suggests that the near-surface soil was affected immediately by rainfall, but at Naqu, SM in the middle and deep layers $(30,40$, and $50 \mathrm{~cm}$ ) showed a lagged strongest response to precipitation of 5 to 7 days (Table 2).

At Jiali, the total precipitation during the growing season in 2015 was $582 \mathrm{~mm}$, which was the most recorded at the three stations in this study. Jiali also showed two main periods of rainfall, 10 May to 14 July and 6 August to 20 September, with amounts of 300 and $250 \mathrm{~mm}$, respectively (Figure 7). Precipitation had a significant effect on SM (except at $50 \mathrm{~cm}$ ), particularly for depths of 10 and $20 \mathrm{~cm}$ (Table 4). The middle layers $(30 \mathrm{~cm}$ and $40 \mathrm{~cm})$ showed a lagged response to rainfall of 1 day, and the $50 \mathrm{~cm} \mathrm{SM}$ showed a lag of 5 days (Table 2).

\section{Discussion and Conclusions}

For most natural ecosystems, changes in air temperature could affect evaporation and soil temperature and lead to increase or decrease in soil respiration and plant photosynthesis, which in turn lead to changes in SM levels $[11,19,20]$. Generally, when SM increased, rate of evaporation also increased, which further caused latent heat flux from net radiation for evapotranspiration to increase. Thus, sensible heat flux decreases, and surface air temperature decreases [9]. Furthermore, air temperature decreases as SM increases [21], and Whan et al. [22] found a negative relationship between SM and extreme maximum summer temperatures in Europe. However, Zhang et al. [5] suggested 


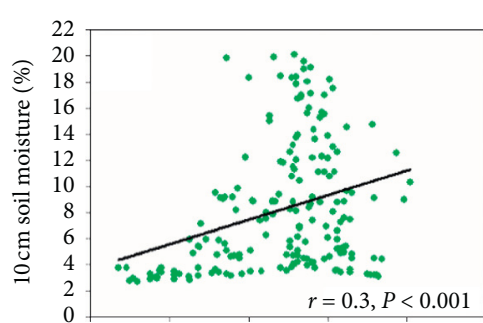

(a)

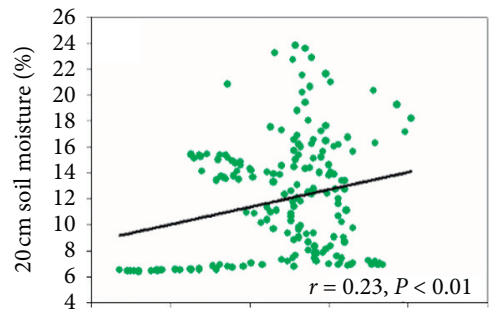

(b)

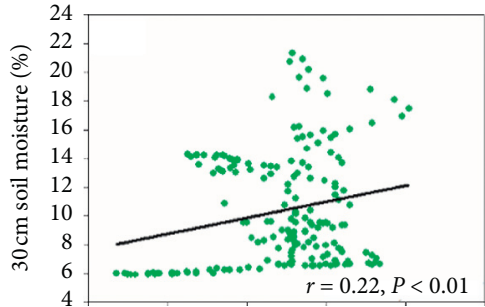

(c)

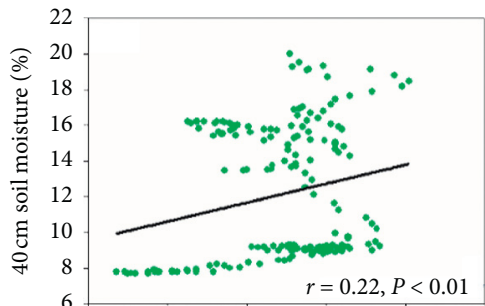

(d)

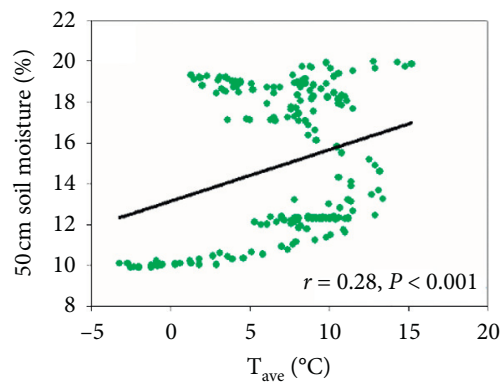

(e)

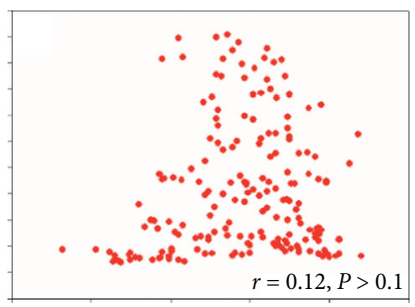

(f)

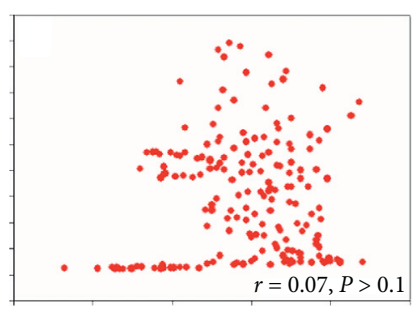

(g)

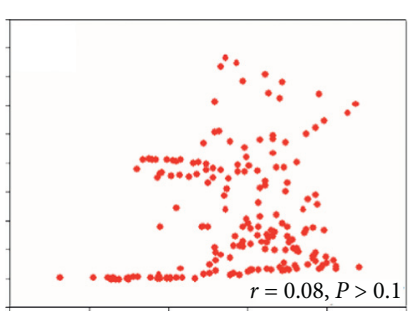

(h)

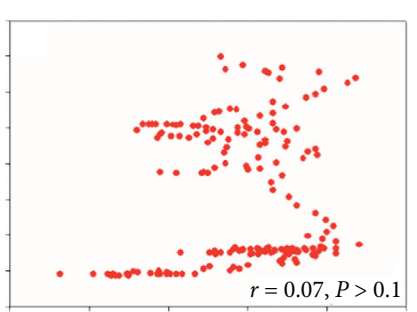

(i)

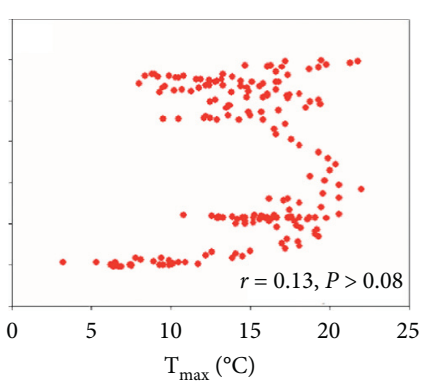

(j)

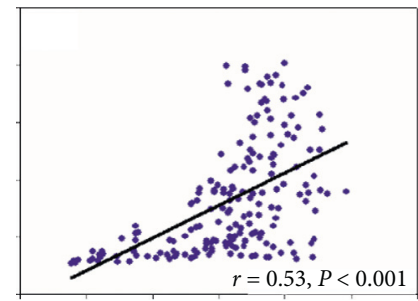

(k)

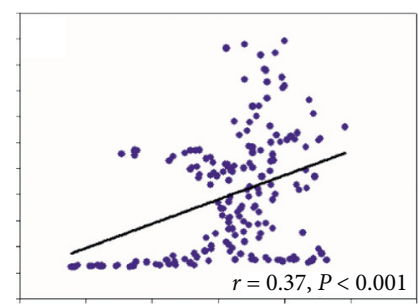

(l)

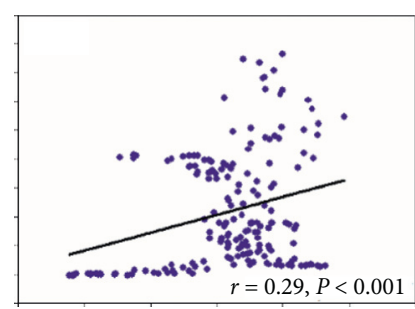

(m)

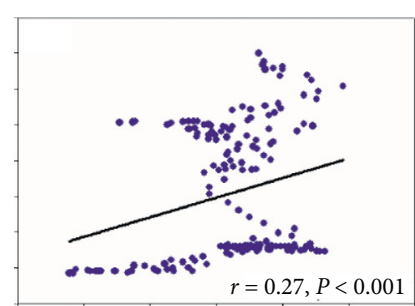

(n)

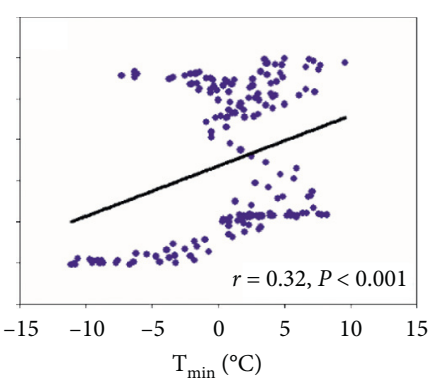

(o)

Figure 2: Correlations between air temperature and soil moisture at Naqu. 


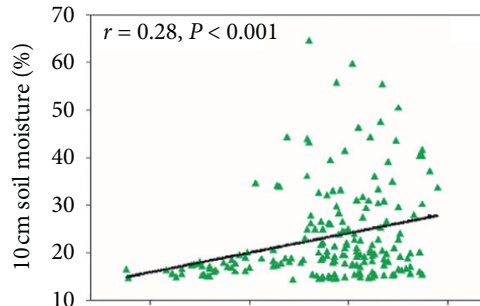

(a)

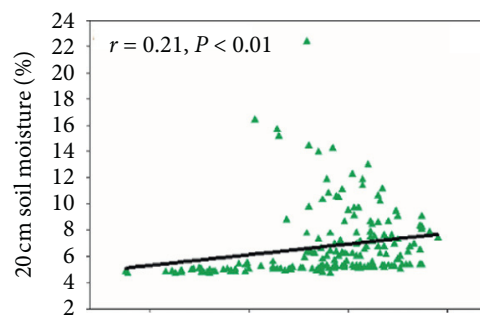

(b)

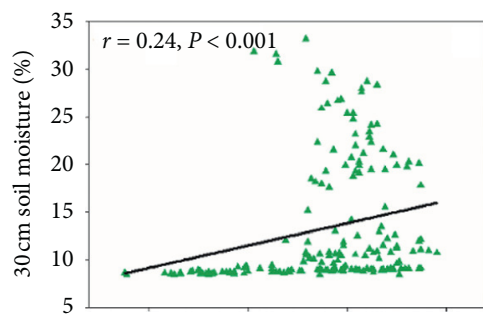

(c)

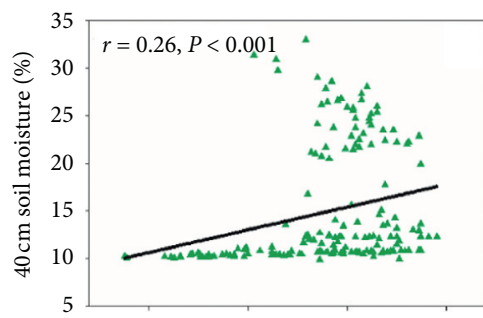

(d)

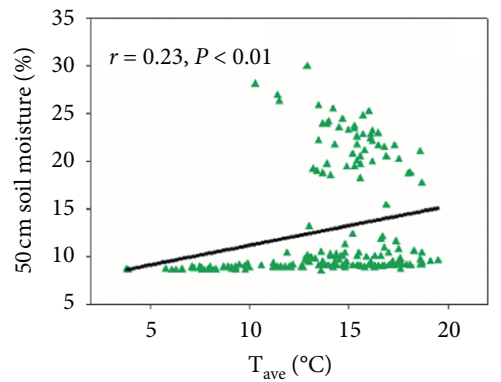

(e)

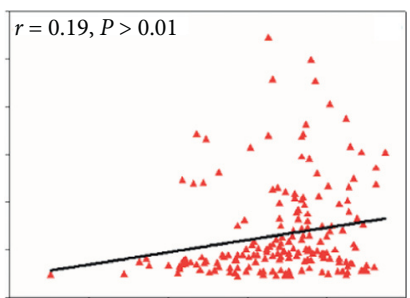

(f)

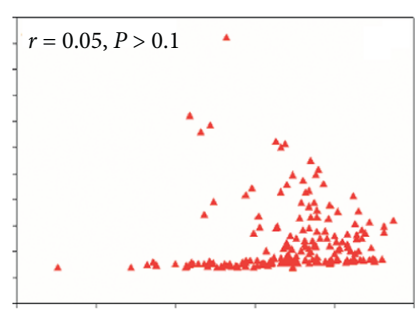

(g)

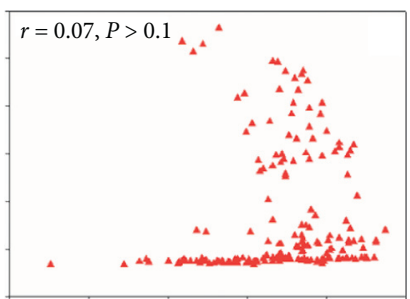

(h)

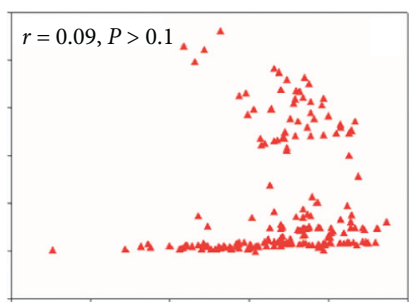

(i)

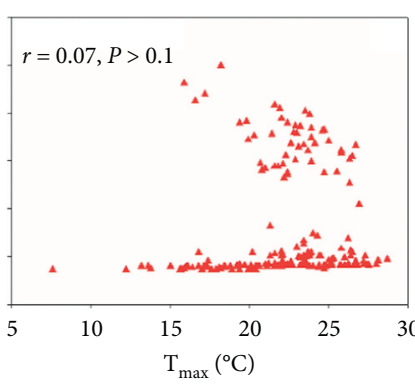

(j)

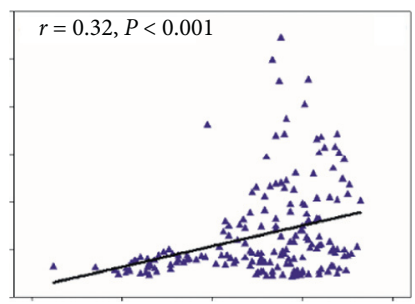

(k)

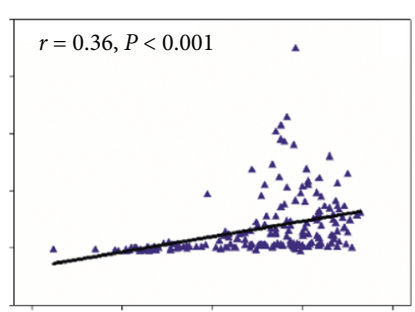

(l)

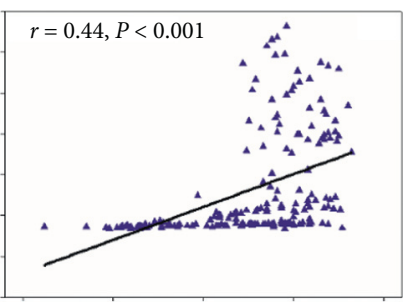

(m)

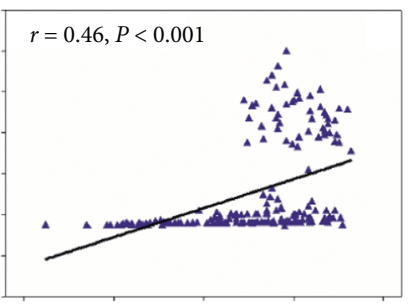

(n)

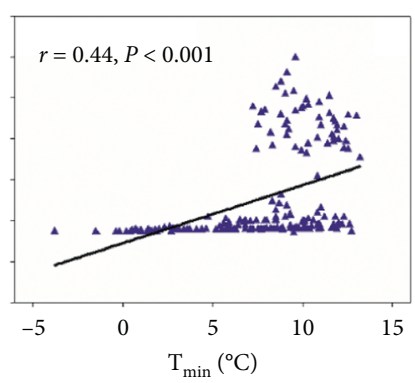

(o)

Figure 3: Correlations between air temperature and soil moisture at Zedang. 


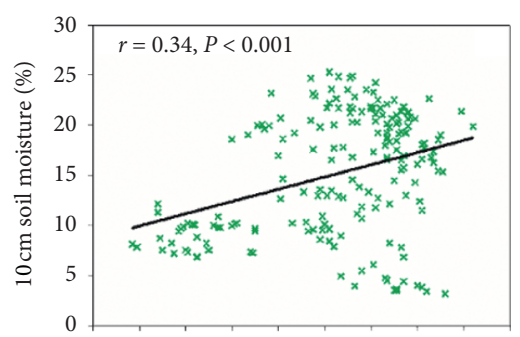

(a)

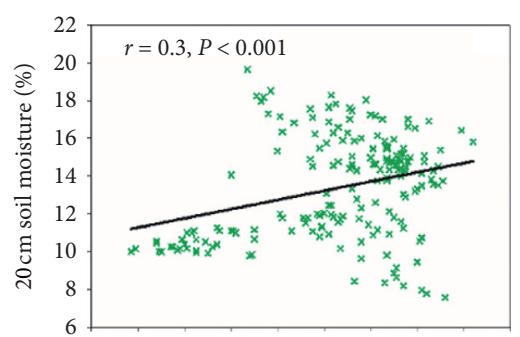

(b)

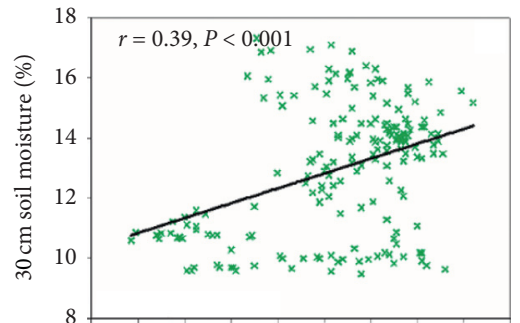

(c)

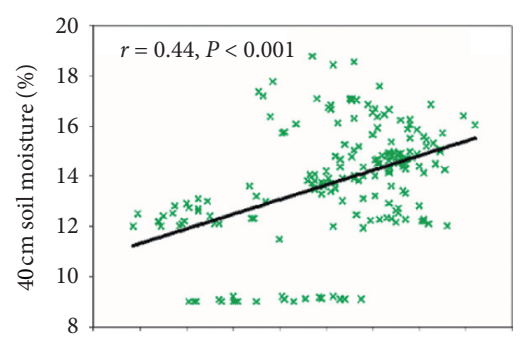

(d)

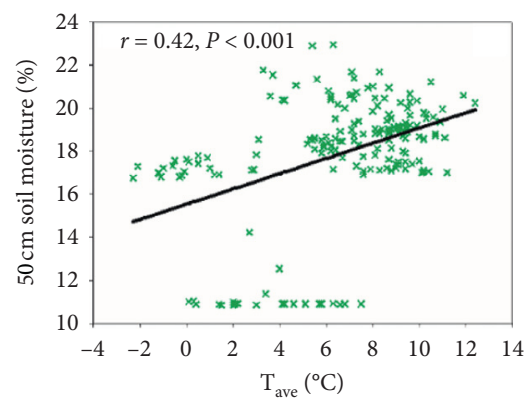

(e)

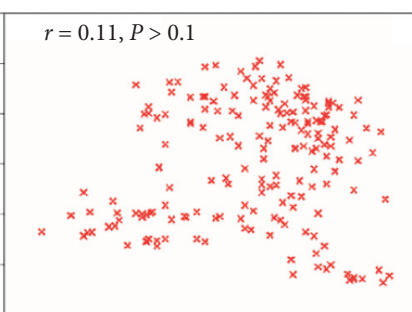

(f)

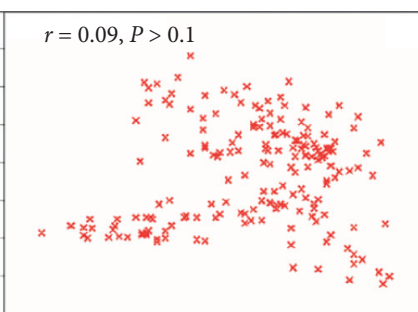

(g)

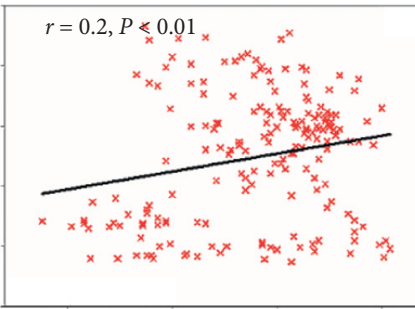

(h)

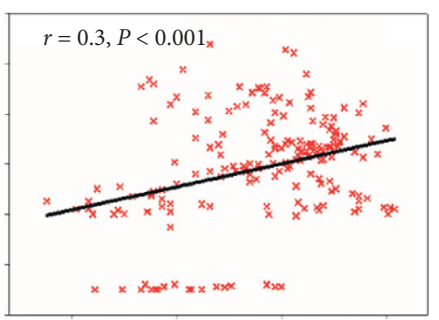

(i)

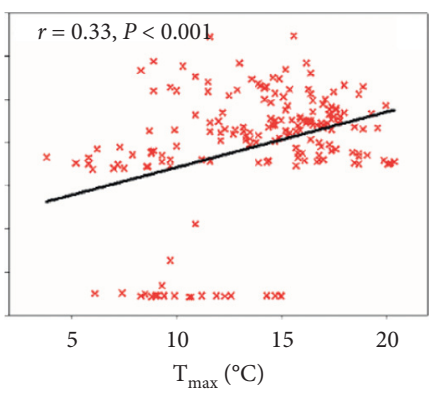

(j)

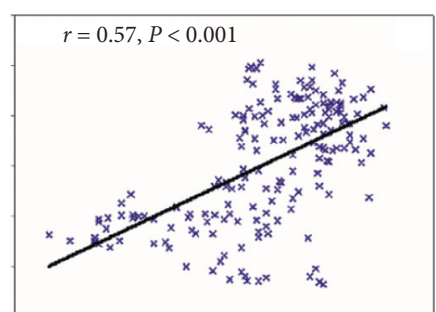

(k)

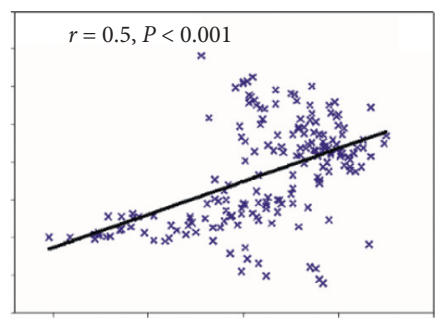

(l)

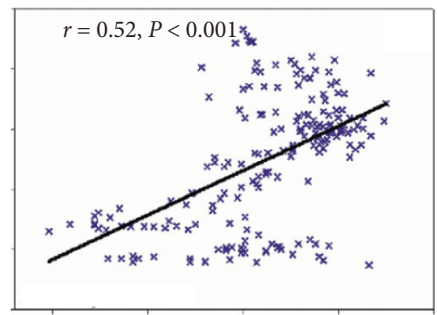

(m)

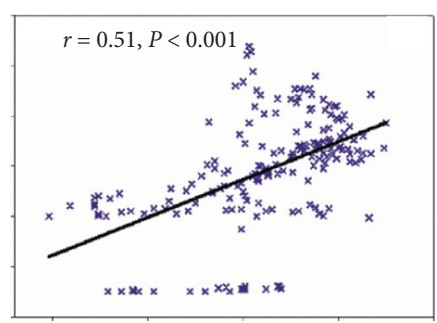

(n)

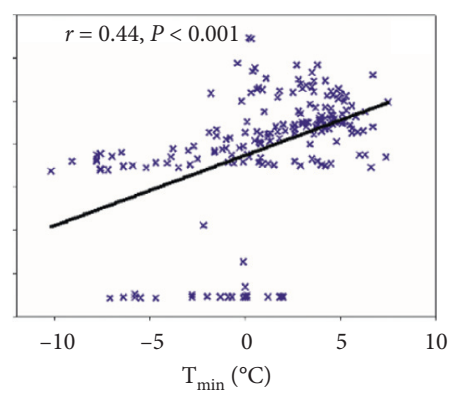

(o)

Figure 4: Correlations between air temperature and soil moisture at Jiali. 


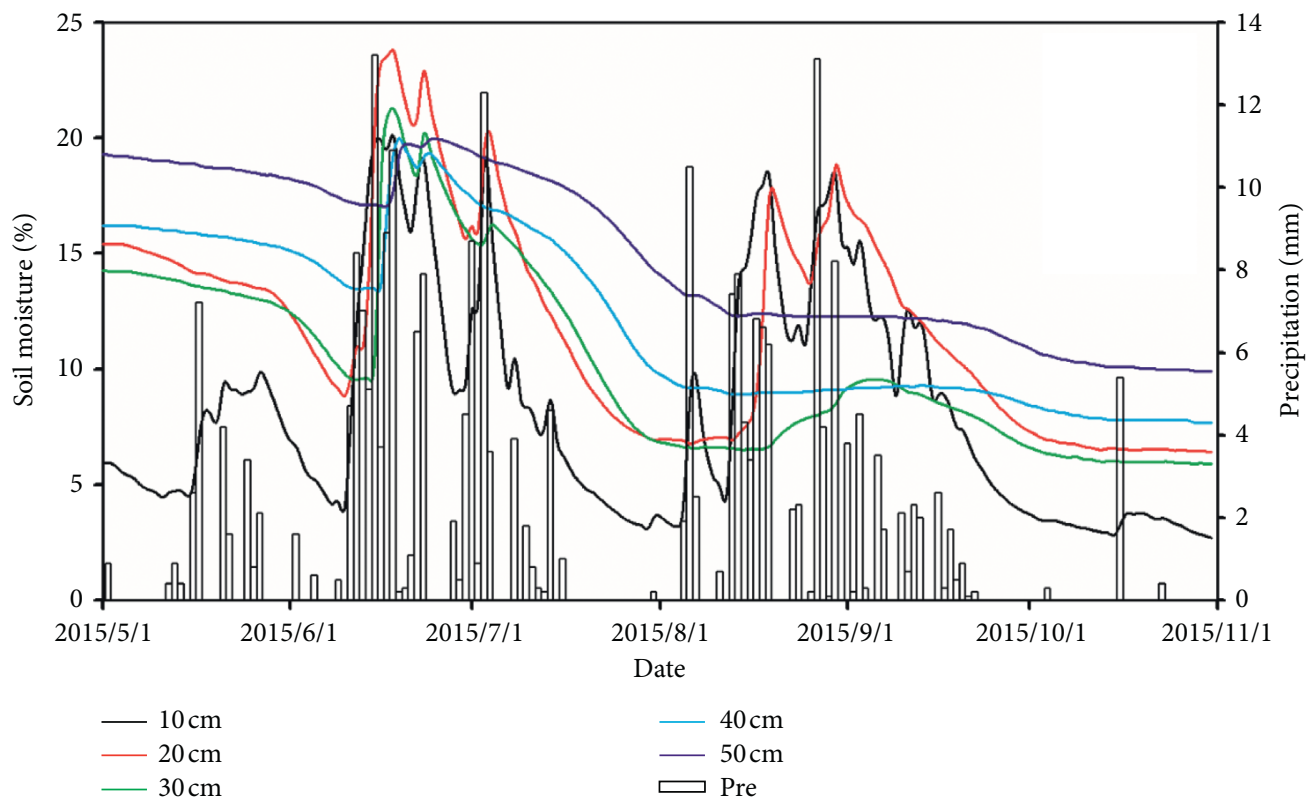

FIgURE 5: Precipitation and SM levels in the soil profile at Naqu from May to October 2015.

TABLE 1: Correlations between precipitation and SM through the soil profile at Naqu.

\begin{tabular}{|c|c|c|c|c|c|}
\hline & Precipitation & $10 \mathrm{~cm}$ & $20 \mathrm{~cm}$ & $30 \mathrm{~cm}$ & $40 \mathrm{~cm}$ \\
\hline 10 & $0.61^{* *}$ & & & & \\
\hline 20 & $0.34^{* *}$ & $0.77^{* *}$ & & & \\
\hline 30 & 0.16 & $0.43^{* *}$ & $0.82^{* *}$ & & \\
\hline 40 & 0.12 & $0.28^{* *}$ & $0.68^{* *}$ & $0.95^{* *}$ & \\
\hline 50 & 0.1 & $0.23^{*}$ & $0.62^{* *}$ & $0.88^{* *}$ & $0.97^{* *}$ \\
\hline
\end{tabular}

$* *$ and $* *$ indicate that the correlation coefficients are statistically significant at the $99 \%$ and $99.9 \%$ levels, respectively (Student's $t$-test).

TABLE 2: The lag correlation coefficients between middle and deep layers' SM and precipitation.

\begin{tabular}{|c|c|c|c|c|c|c|}
\hline & Lag (days) $(\mathrm{cm})$ & 1 & 2 & 3 & 5 & 7 \\
\hline \multirow{3}{*}{ Naqu } & 30 & 0.23 & $0.26^{* *}$ & $0.29^{* *}$ & $0.35^{* *}$ & \\
\hline & 40 & 0.14 & 0.17 & 0.19 & 0.23 & $0.24^{* *}$ \\
\hline & 50 & 0.12 & 0.13 & 0.14 & 0.16 & 0.18 \\
\hline \multirow{3}{*}{ Zedang } & 30 & $0.31^{* *}$ & $0.33^{* *}$ & $0.32^{* *}$ & $0.36^{* *}$ & \\
\hline & 40 & $0.28^{* *}$ & $0.31^{* *}$ & $0.3^{* *}$ & $0.3^{* *}$ & $0.35^{* *}$ \\
\hline & 50 & $0.25^{* *}$ & $0.28^{* *}$ & $0.28^{* *}$ & $0.29^{* *}$ & $0.35^{* *}$ \\
\hline \multirow{3}{*}{ Jiali } & 30 & $0.4^{* *}$ & & & & \\
\hline & 40 & $0.35^{* *}$ & & & & \\
\hline & 50 & 0.2 & $0.24^{* *}$ & $0.25^{* *}$ & $0.28^{* *}$ & \\
\hline
\end{tabular}

** indicates that the correlation coefficients are statistically significant at the $99.9 \%$ level (Student's $t$-test). Bold numbers indicate the maximum correlation coefficients.

that air temperature is an important driver of spatiotemporal changes in SM as it controls snowmelt on the QTP, which further increases runoff and SM levels. In the present study, both $\mathrm{T}_{\text {ave }}$ and $\mathrm{T}_{\mathrm{min}}$ showed significant positive relationships with SM among all depths at the three stations, and the correlation coefficients between $\mathrm{T}_{\min }$ and $\mathrm{SM}$ were higher than those between $\mathrm{T}_{\text {ave }}$ and SM. This suggests that temperature, especially low temperature, could better promote SM conservation across the various climate zones and ecosystems of the QTP. However, no obvious relationship between $\mathrm{T}_{\max }$ and SM was found in the present study; only the surface layer of Zedang and 30 to $50 \mathrm{~cm}$ layers in Jiali have weakly positive correlation, and this might be caused by the different soil properties among the three sites. As we all know, for most ecosystems, the evaporation or respiration had a significant positive correlation with air temperature, it means that the higher air temperature was benefit for evaporation or respiration, and negative relationship with soil water. However, because $\mathrm{T}_{\max }$ was limited by the cold climate and high altitude on the QTP, in this study, the mean 


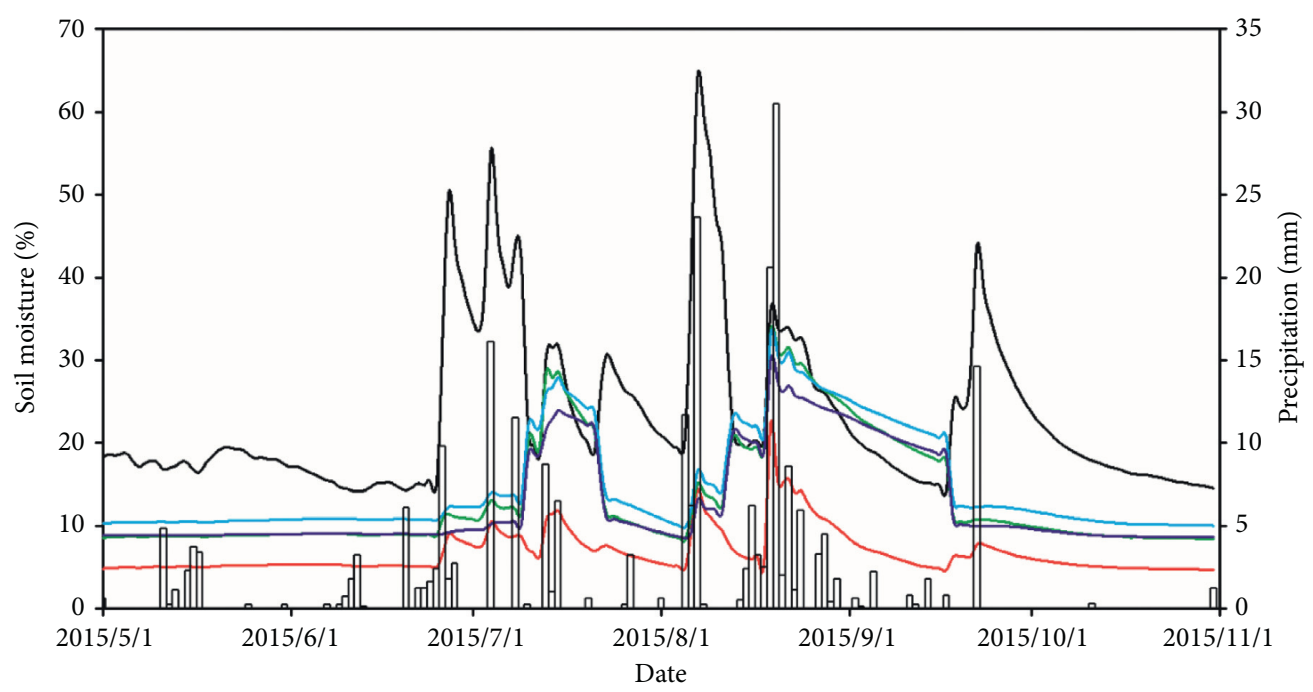

FIGURE 6: Precipitation and SM levels in the soil profile at Zedang from May to October 2015.

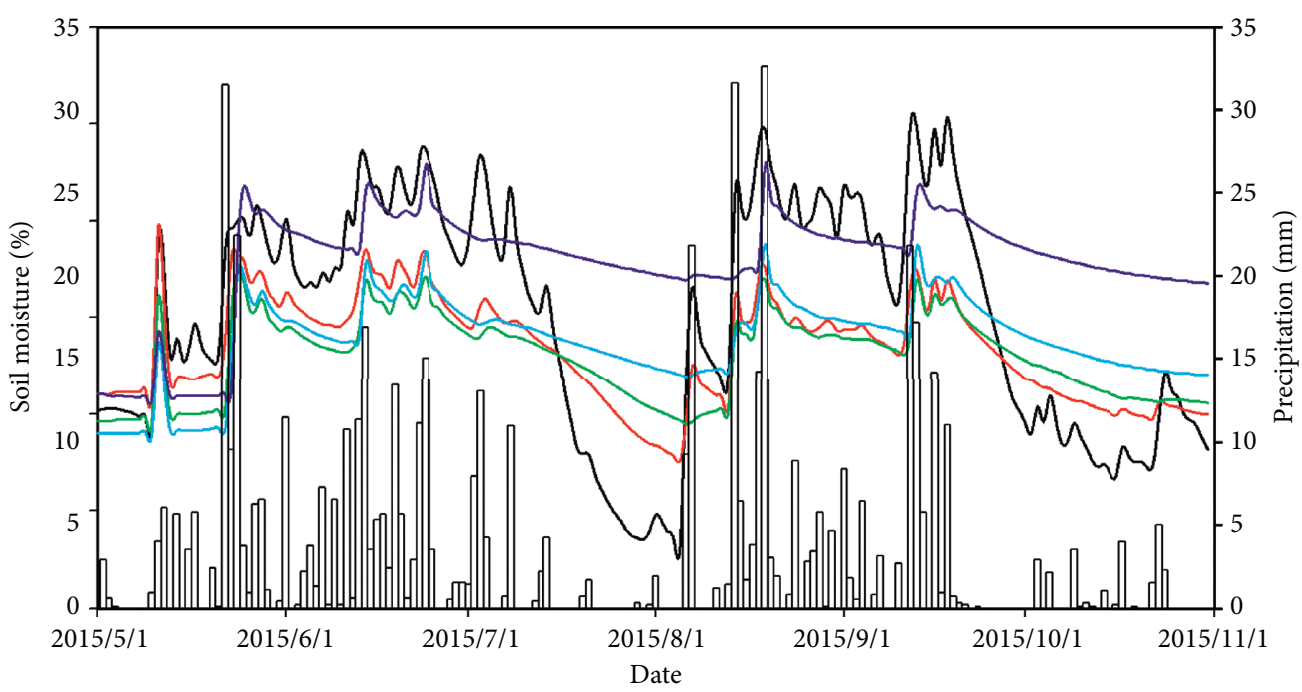

Figure 7: Precipitation and SM levels in the soil profile at Jiali from May to October 2015.

TABLE 3: Correlations between precipitation and SM through the soil profile at Zedang.

\begin{tabular}{lcccc}
\hline & Precipitation & $10 \mathrm{~cm}$ & $20 \mathrm{~cm}$ & $30 \mathrm{~cm}$ \\
\hline 10 & $0.41^{* *}$ & & & \\
20 & $0.56^{* *}$ & $0.7^{* *}$ & & \\
30 & $0.31^{* *}$ & $0.24^{* *}$ & $0.74^{* *}$ & $0.99^{* *}$ \\
40 & $0.29^{* *}$ & $0.21^{* *}$ & $0.7^{* *}$ & $0.99^{* *}$ \\
50 & $0.26^{* *}$ & 0.14 & $0.65^{* *}$ & $1.0^{* *}$ \\
\hline
\end{tabular}

* indicate that the correlation coefficients are statistically significant at the $99 \%$ and $99.9 \%$ levels, respectively (Student's $t$-test).

TABLE 4: Correlations between precipitation and SM through the soil profile at Jiali.

\begin{tabular}{lcccc}
\hline$(\mathrm{cm})$ & Precipitation & $10 \mathrm{~cm}$ & $20 \mathrm{~cm}$ & $30 \mathrm{~cm}$ \\
\hline 10 & $0.47^{* *}$ & & & \\
20 & $0.45^{* *}$ & $0.93^{* *}$ & & \\
30 & $0.34^{* *}$ & $0.82^{* *}$ & $0.91^{* *}$ & $0.92^{* *}$ \\
40 & $0.25^{* *}$ & $0.67^{* *}$ & $0.72^{* *}$ & $0.75^{* *}$ \\
50 & 0.12 & $0.47^{* *}$ & $0.5^{* *}$ & $0.94^{* *}$ \\
\hline
\end{tabular}

$* *$ indicate that the correlation coefficients are statistically significant at the $99 \%$ and $99.9 \%$ levels, respectively (Student's $t$-test). 
$\mathrm{T}_{\max }$ of the three sites in growth season was $14.6^{\circ} \mathrm{C}, 22.2^{\circ} \mathrm{C}$, and $13.9^{\circ} \mathrm{C}$, respectively, not much hot. Thus, we inferred that the pronounced increase in evaporation or respiration expected under $\mathrm{T}_{\max }$ was not significantly high. Moreover, the $\mathrm{T}_{\max }$ duration of everyday was also limited, only for a very short period in everyday on the QTP, so the evaporation or respiration kept a lower level in general, meaning that SM at the study sites was relatively high. Furthermore, in this study, the mean $\mathrm{T}_{\min }$ of the three sites in growth season was $0.8^{\circ} \mathrm{C}, 7.8^{\circ} \mathrm{C}$, and $1.1^{\circ} \mathrm{C}$, respectively. It means that $\mathrm{T}_{\min }$ often below ice point and the soil water was frozen in soil, and thus the respiration of plant and microorganism was limited, and they were hard to use soil water effectively, so the water use efficiency (WUE) is decreased, and it is helpful to keep SM in high level on the QTP $[3,15]$. In addition, the $\mathrm{T}_{\min }$ could not only significantly effect on the surface layer but also for the middle and deep layers' SM; however, the $\mathrm{T}_{\max }$ only have a weakly impact on the surface layers' SM. Maybe, this is why $\mathrm{T}_{\min }$ has a stronger effect on SM than $\mathrm{T}_{\max }$ on the QTP.

Precipitation exerts an important control on SM [23], with higher SM levels being associated with higher precipitation on the QTP [5]. Precipitation infiltrates directly into soil and so increases SM levels. Furthermore, precipitation can lead to decreases in air and soil temperatures, which slows evaporation and respiration which will reduce the consumption of soil water [24]. But in this study, we did not find an interactive effect of precipitation and air temperature (including $\mathrm{T}_{\min }, \mathrm{T}_{\text {ave }}$, and $\mathrm{T}_{\max }$ ) on $\mathrm{SM}$ (Table 5), which suggested that precipitation and air temperature could independently impact on the SM in this study, and also this is a different point with other research studies $[11,23]$. For the three stations in this research, precipitation showed a significant positive correlation with SM in the shallow soil layers at all three observational stations, which indicated that a tight relationship between precipitation and SM was not influenced by the different conditions characterizing climatic zones on the QTP. However, for the middle and deep layers, there was a time-lagged effect of precipitation on SM, with the strongest signal occurring 5 to 7 days after rainfall (Table 2). The lagged response of SM to precipitation was just only in middle and deep layers, which suggested that the precipitation process was very short and the precipitation intensity was very weak, which may only influence SM in surface layers, and it had no lagged effects on middle and deep layers' SM. Contrarily, if the precipitation could keep a long process and with a stronger precipitation intensity, it may not only directly impact surface layers but also had time-lagged effects on middle and deep layers. Therefore, the lag of soil moisture content to precipitation was different under different precipitation conditions.

In summary, we investigated the relationship between SM and air temperature and SM and precipitation, during a single growing season in three different climatic zones on the Qinghai-Tibet Plateau. We found that the effect of $\mathrm{T}_{\max }$ on $\mathrm{SM}$ was not significant at Naqu and Zedang (only weak effects on surface layer), and it influences SM only in the middle and deep soil layers at Jiali. However, $\mathrm{T}_{\text {ave }}$ and $\mathrm{T}_{\text {min }}$ had a well-defined effect on SM at all three stations, with $\mathrm{T}_{\text {min }}$ having a stronger effect on $\mathrm{SM}$ than $\operatorname{did} \mathrm{T}_{\text {ave }}$.
TABLE 5: Correlations between precipitation and air temperature of three stations.

\begin{tabular}{lcccc}
\hline & Stations & $\mathrm{T}_{\min }$ & $\mathrm{T}_{\text {ave }}$ & $\mathrm{T}_{\max }$ \\
\hline Naqu & Precipitation & 0.35 & 0.08 & -0.05 \\
Zedang & Precipitation & 0.13 & -0.08 & -0.21 \\
Jiali & Precipitation & 0.11 & -0.05 & -0.16 \\
\hline
\end{tabular}

Precipitation had a clear influence on SM at the studied sites, especially in the near-surface layers, with a directly significant positive correlation between these two variables. There was a time-lagged relationship between precipitation and SM in the middle and deep layers, with the response reaching a maximum level after 5 to 7 days among all three stations. Although we have got some interesting and new results, there were still a lot of uncertain factors in this research, for example, we only chose three studied sites and one growth season on the QTP and did not consider the effects of vegetation, soil temperature, and global warming. Thus, all of these are needed to be dealt with carefully in our future work.

\section{Data Availability}

The meteorological observation data and soil moisture data were taken from http://data.cma.cn/data/cdcindex/cid/ 6d1b5efbdcbf9a58.html.

\section{Conflicts of Interest}

The authors declare that there are no conflicts of interest regarding the publication of this paper.

\section{Authors' Contributions}

Qingyan Xie and Yufei Zhao collected the data. Qingyan Xie, Yufei Zhao, and Jianping Li analyzed the data, contributed to writing, and reviewed the article.

\section{Acknowledgments}

This study was supported by the National Natural Science Foundation of China (NSFC) Project (41790474), National Natural Science Foundation of China (NSFC) (Development of Data Sharing Platform of the Tibetan Plateau's MultiSource Land-Atmosphere System Information) (91637313), Shandong Natural Science Foundation Project (ZR2019ZD12), and Fundamental Research Funds for the Central Universities (201962009).

\section{References}

[1] Y. Gao, D. J. Cooper, and X. Ma, "Phosphorus additions have no impact on plant biomass or soil nitrogen in an alpine meadow on the Qinghai-Tibetan Plateau, China," Applied Soil Ecology, vol. 106, pp. 18-23, 2016.

[2] S. Piao, P. Ciais, Y. Huang et al., "The impacts of climate change on water resources and agriculture in China," Nature, vol. 467, no. 7311, pp. 43-51, 2010. 
[3] M. Yang, T. Yao, X. Gou, T. Koike, and Y. He, "The soil moisture distribution, thawing-freezing processes and their effects on the seasonal transition on the Qinghai-Xizang (Tibetan) plateau," Journal of Asian Earth Sciences, vol. 21, no. 5, pp. 457-465, 2003.

[4] K. Yang, B. S. Ye, D. G. Zhou et al., "Response of hydrological cycle to recent climate changes in the Tibetan Plateau," Climatic Change, vol. 109, no. 3-4, pp. 517-534, 2011.

[5] Q. Zhang, K. Fan, V. P. Singh, C. Song, C.-Y. Xu, and P. Sun, "Is Himalayan-Tibetan Plateau "drying?" Historical estimations and future trends of surface soil moisture," Science of the Total Environment, vol. 658, pp. 374-384, 2019.

[6] K. C. Chow, J. C. L. Chan, X. L. Shi, Y. M. Liu, and Y. H. Ding, "Time-lagged effects of spring Tibetan Plateau soil moisture on the monsoon over China in early summer," International Journal of Climatology, vol. 28, no. 1, pp. 55-67, 2008.

[7] K. Fan, Q. Zhang, V. P. Singh et al., "Spatiotemporal impact of soil moisture on air temperature across the Tibet Plateau," Science of the Total Environment, vol. 649, pp. 1338-1348, 2019.

[8] Z.-X. Shen, Y.-L. Li, and G. Fu, "Response of soil respiration to short-term experimental warming and precipitation pulses over the growing season in an alpine meadow on the Northern Tibet," Applied Soil Ecology, vol. 90, pp. 35-40, 2015.

[9] Z. Ding, Y. Wang, and R. Lu, "An analysis of changes in temperature extremes in the Three River Headwaters region of the Tibetan Plateau during 1961-2016," Atmospheric Research, vol. 209, pp. 103-114, 2018.

[10] S. Sitch, B. Smith, I. C. Prentice et al., "Evaluation of ecosystem dynamics, plant geography and terrestrial carbon cycling in the LPJ dynamic global vegetation model," Global Change Biology, vol. 9, no. 2, pp. 161-185, 2003.

[11] S. I. Seneviratne, T. Corti, E. L. Davin et al., "Investigating soil moisture-climate interactions in a changing climate: a review," Earth-Science Reviews, vol. 99, no. 3-4, pp. 125-161, 2010.

[12] Z. Su, J. Wen, L. Dente et al., “The Tibetan Plateau observatory of plateau scale soil moisture and soil temperature (Tibet-Obs) for quantifying uncertainties in coarse resolution satellite and model products," Hydrology and Earth System Sciences, vol. 15, no. 7, pp. 2303-2316, 2011.

[13] X. Liu and T. Luo, "Spatiotemporal variability of soil temperature and moisture across two contrasting timberline ecotones in the sergyemla mountains, southeast Tibet," Arctic, Antarctic, and Alpine Research, vol. 43, no. 2, pp. 229-238, 2011.

[14] Q. Y. Xie, X. D. Wang, Y. H. Gao, and M. Y. Zhang, "Short term effect of precipitation amount change on greenhouse gas emissions from alpine grassland in the eastern Qinghai-Tibetan Plateau," Range Management and Agroforestry, vol. 38, no. 2, pp. 151-157, 2017.

[15] J. Z. Wang, L. Yan, H. D. Wu, and X. M. Kang, "Study of alpine grass degradation in Northern Tibet based on analytical hierarchy process," Chinese Journal of Applied \& Environmental Biology, vol. 25, no. 6, pp. 1-12, 2019, in Chinese.

[16] E. F. Dai, Z. Wu, H. H. Lu, and H. Fu, "Linear spectral unmixing-based method for the detection of land cover change in Naidong County, Qinghai-Tibet Plateau," Progress in Geography, vol. 34, no. 7, pp. 854-861, 2015, in Chinese.

[17] M. P. Sun, S. Y. Liu, X. J. Yao, and L. Li, "The cause and potential hazard of glacial lake outburst flood occurred on July 5, 2013 in Jiali County, Tibet," Journal of Glaciology and Geocryology, vol. 36, no. 1, pp. 158-165, 2014, in Chinese.
[18] M. F. Deng, N. S. Chen, T. Wang, and H. T. Ding, "Fluctuation of daily rainfall extreme in Southeastern Tibet," Journal of Natural Disasters, vol. 26, no. 2, pp. 152-159, 2017, in Chinese.

[19] P. C. D. Milly, "Potential evaporation and soil moisture in general circulation models," Journal of Climate, vol. 5, no. 3, pp. 209-226, 1992.

[20] S. U. Susha Lekshmi, D. N. Singh, and M. Shojaei Baghini, “A critical review of soil moisture measurement," Measurement, vol. 54, pp. 92-105, 2014.

[21] C. Schwingshackl, M. Hirschi, and S. I. Seneviratne, "Quantifying spatiotemporal variations of soil moisture control on surface energy balance and near-surface air temperature," Journal of Climate, vol. 30, no. 18, pp. 71057124, 2017.

[22] K. Whan, J. Zscheischler, R. Orth et al., "Impact of soil moisture on extreme maximum temperatures in Europe," Weather and Climate Extremes, vol. 9, pp. 57-67, 2015.

[23] C. Hohenegger, P. Brockhaus, C. S. Bretherton, and C. Schär, "The soil moisture-precipitation feedback in simulations with explicit and parameterized convection," Journal of Climate, vol. 22, no. 19, pp. 5003-5020, 2009.

[24] S. Cheng, X. Guan, J. Huang, F. Ji, and R. Guo, "Long-term trend and variability of soil moisture over East Asia," Journal of Geophysical Research: Atmospheres, vol. 120, no. 17, pp. 8658-8670, 2015. 